\title{
High-Performance Liquid Chromatographic Separation of Histidine Oligopeptides
}

\author{
Jun-ichi Ueda*, Akira Hanaki*, Tadashi Yasuhara**, Terumi NakaJima** \\ and Shosuke SoFUKU*** \\ *National Institute of Radiological Sciences, Anagawa, Chiba 260, Japan \\ **Faculty of Pharmaceutical Sciences, University of Tokyo, Hongo, Tokyo 113, Japan \\ *** Department of Chemistry, College of Science, Rikkyo University, \\ Nishi-Ikebukuro, Tokyo 171, Japan
}

\begin{abstract}
Histidine oligopeptides which differ by one histidyl residue in length up to a total of 20 amino acid residues were separated by high-performance liquid chromatography on a commercially available strong cation-exchange column (TSK gel SP$2 \mathrm{SW}$ ) using isocratic elution with a $\mathrm{NaCl}$ solution.
\end{abstract}

Keywords High-performance liquid chromatography, histidine peptides, cation-exchanger, silica gel

High-performance liquid chromatography (HPLC) is a useful means for separating and purifying biologically relevant polyelectrolytes. The electrolytes could be separated chromatographically on gel filtration columns in response to their molecular size and shape, and on ionexchanger columns in response to the electrolytic charge. This paper describes an attempt to separate histidine oligopeptides, (His) ${ }_{n}$ Gly $(n=2-19)$, which were synthesized by a conventional solid-phase mehod, on various cation-exchanger columns. The histidyl side chain is the most important metal-coordinating group involved in the active site of metal enzymes. ${ }^{1}$

\section{Experimental}

\section{Reagents}

(His) ${ }_{4}$ Gly and (His) ${ }_{9}$ Gly as internal reference were synthesized by a conventional liquid-phase method and identified by FBA mass spectrometry: (His) ${ }_{4} \mathrm{Gly}$; $(\mathrm{M}+\mathrm{H})^{+}=m / z$ 622, and (His) $)_{9} \mathrm{Gly} ;(\mathrm{M}+\mathrm{H})^{+}=m / z 1310$. (His) $)_{n}$ Gly were synthesized by a solid-phase method with an LKB BIOLYNX 4175 (Bromma, Sweden). The starting materials were Fmoc-His(Boc)-OPFP, FmocGly-OPFP, and polyamide resin.

\section{HPLC apparatus and columns}

A TRI ROTAR SR2 HPLC system (JASCO Co.). The columns used were TSKgel SP-2SW $(250 \times 4.6 \mathrm{~mm}$ i.d.), SP-NPR ( $35 \times 4.6 \mathrm{~mm}$ i.d.), and SP-5PW (75× $7.5 \mathrm{~mm}$ i.d.) (TOSOH Co.). TSKgel SP-2SW is porous spherical silica gel whose surfaces are chemically bonded with sulfopropyl groups. TSKgel SP-NPR is a nonporous spherical hydrophilic resin, and TSKgel SP-5PW is a porous spherical hydrophilic resin, both having sulfopropyl groups. Eluants were used which contained various concentrations (from 0.4 to $1.5 \mathrm{M}$ ) of $\mathrm{NaCl}$; the pHs were adjusted by adding $\mathrm{H}_{3} \mathrm{PO}_{4}-\mathrm{NaH}_{2} \mathrm{PO}_{4}$. The final concentration of phosphate was $10 \mathrm{mM}$. The flow rate and column oven temperature were $1.0 \mathrm{ml} / \mathrm{min}$ and $50^{\circ} \mathrm{C}$, respectively.

\section{Results and Discussion}

The peptides are required to have electric charges that are adequate to be adsorbed on ion-exchanger columns. Since the average $\mathrm{p} K_{\mathrm{a}}$ of the imidazole residues in polyhistidine were shown to be $6.1^{2}$, the $\mathrm{pH}$ of the eluant was set at 4.1 , where the peptides might be positively charged.

Table 1 shows the capacity factors $\left(k^{\prime}\right)$ of $(\mathrm{His})_{4} \mathrm{Gly}$ and (His), Gly for three different types of columns (TSK gel SP-2SW, SP-NPR, and SP-5PW). The TSKgel

Table $1 k^{\prime}$ values of (His) ${ }_{4} \mathrm{Gly}$ and (His) $)_{9} \mathrm{Gly}$ on cationexchange columns

\begin{tabular}{lccc}
\hline & \multicolumn{3}{c}{ TSKgel } \\
\cline { 2 - 4 } & SP-2SW & SP-NPR & SP-5PW \\
\hline (His) 4Gly $_{\text {(His) }}$ Gly & 0.88 & 3.0 & 1.22 \\
(H) & 8.0 & 200 & 30 \\
\hline
\end{tabular}

The eluant used is $10 \mathrm{mM} \mathrm{NaH}_{2} \mathrm{PO}_{4}$ containing $1.0 \mathrm{M} \mathrm{NaCl}$ (pH 4.1). $\quad k^{\prime}$ is related to retention time as $k^{\prime}=\left(t_{\mathrm{R}}-t_{0}\right) / t_{0}$, in which $t_{0}$ and $t_{\mathrm{R}}$ are retention time of a non-sorbed substance and apparent retention time, respectively. 


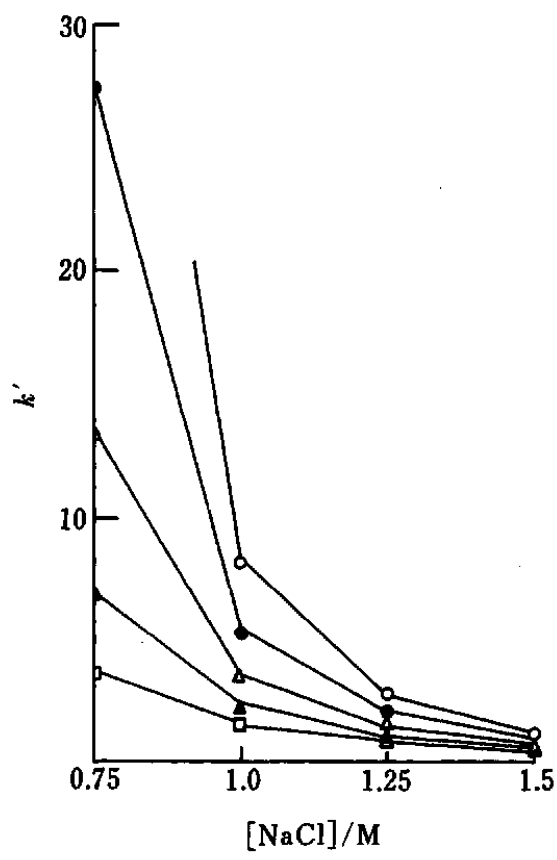

Fig. 1 Relationship between $k^{\prime}$ and the $\mathrm{NaCl}$ concentration in the mobile phase. $O$, (His) ${ }_{9} \mathrm{Gly} ; O,(\mathrm{His})_{8} \mathrm{Gly} ; \Delta,(\mathrm{His})_{7} \mathrm{Gly}$; $\Delta,{\text { (His })_{6} \mathrm{Gly} ;}$, , (His) $)_{5} \mathrm{Gly}$.
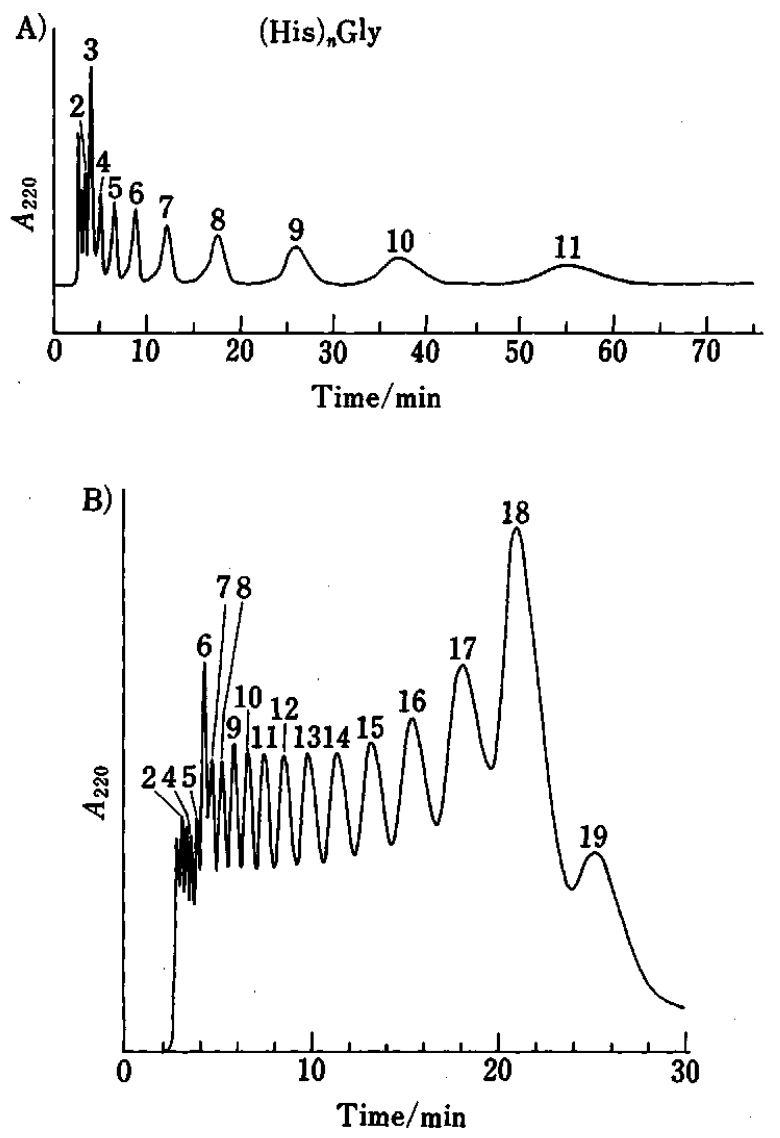

Fig. 2 Chromatogram of mixtures of (His) $)_{n}$ Gly $(n=2-19)$. The separation was performed on a TSKgel SP-2SW column with $1.0 \mathrm{M}(\mathrm{A})$ and $1.5 \mathrm{M}(\mathrm{B}) \mathrm{NaCl}$ in $10 \mathrm{mM} \mathrm{NaH}_{2} \mathrm{PO}_{4}$ at a flow rate of $1.0 \mathrm{ml} / \mathrm{min}$ and $50^{\circ} \mathrm{C}$.
SP-2SW column appeared to adsorb the peptides loosely. Both the SP-NPR and SP-5PW columns tightly adsorbed high molecular weight peptides, probably due to strong hydrophobic interactions with the hydrophobic matrices. In an attempt to practically use an ion-exchanger column for separating high molecular weight peptides, it is recommended to use the TSKgel SP-2SW column.

The binding capacity of ion-exchanger to the charged species depended on the salt contained in the eluant. ${ }^{3}$ The effect of the $\mathrm{NaCl}$ concentration on the chromatographic separation of (His) ${ }_{n}$ Gly mixtures was examined. Mixtures of (His) ${ }_{n}$ Gly from $n=5$ to 9 adsorbed on the TSKgel SP-2SW column were eluted by various concentrations (i.e., $0.75,1.0,1.25$, and $1.5 \mathrm{M}$ ) of $\mathrm{NaCl}$ (pH 4.1 with $10 \mathrm{mM}$ phosphate). Increasing concentrations of $\mathrm{NaCl}$ reduced the $k^{\prime}$ values, as is shown in Fig. 1 . It is expected that lower molecular weight peptides can be separated by using an eluant of lower concentration, and high molecular weight peptides by an eluant of higher concentration. As expected, mixtures of the peptides from $n=2$ to 9 and from 10 to 19 were clearly separated by the difference of one residue using $1.0 \mathrm{M} \mathrm{NaCl}$ and $1.5 \mathrm{M}$ $\mathrm{NaCl}$, respectively. The chromatograms are shown in Fig. 2. The peaks were identified by internal references: (His) ${ }_{4}$ Gly and (His) ${ }_{9}$ Gly. The $k^{\prime}$ value of each peak increased with the number of histidyl residues, as is shown in Fig. 3.

In conclusion, mixtures of (His $)_{n} \mathrm{Gly}(n=2-19)$ were separated on the ion-exchanger column TSKgel SP-

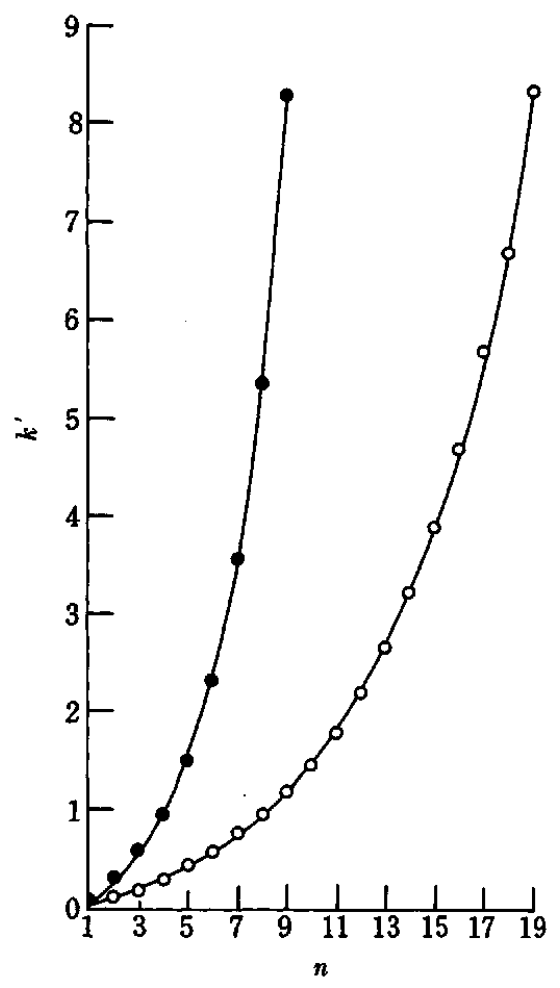

Fig. 3 Relationship between $k^{\prime}$ and $n$ on the (His) $n$ Gly ( $n=$ $2-19)$. (His) ${ }_{n}$ Gly $(n=2-9) ; O$, (His $)_{n}$ Gly $(n=2-19)$. 
$2 \mathrm{SW}$ according to the difference in the number of electric charges. Peptides with less than 10 histidyl residues were clearly separated on the column by isocratic elution with $1.0 \mathrm{M} \mathrm{NaCl}$. Those peptides with more than 11 residues were successfully separated by $1.5 \mathrm{M} \mathrm{NaCl}$. HPLC on a porous strong cation-exchanger is a useful means for separating and purifying oligopeptides with positive charges.

We thank Dr. Hiroshi Nakamura (University of Tokyo) for valuable discussions.

\section{References}

1. W. H. Armstrong, in ACS Symp. Ser. No. 372, 1988, L. Que., Jr. ed., Ch. 1, p. 1 and references therein.

2. R. E. Wasylishen and J. S. Cohen, J. Am. Chem. Soc., 99, 2480 (1977).

3. C. T. Mant and R. S. Hodges, J. Chromatogr., 327, 147 (1985).

(Received April 21, 1992)

(Accepted May 20, 1992) 